Research report

\title{
Possible contribution of epigenetic changes in the development of schizophrenia-like behavior in vasopressin-deficient Brattleboro rats
}

\author{
Kornél Demeter $^{\mathrm{a}, 1}$, Bibiána Török ${ }^{\mathrm{a}, 1}$, Anna Fodor ${ }^{\mathrm{a}}$, János Varga ${ }^{\mathrm{a}}$, Szilamér Ferenczi ${ }^{\mathrm{b}}$, \\ Krisztina J. Kovács ${ }^{\mathrm{b}}$, Ildikó Eszik ${ }^{\mathrm{c}}$, Viktor Szegedi ${ }^{\mathrm{c}}$, Dóra Zelena ${ }^{\mathrm{a}, *}$ \\ a Department of Behavioral Neurobiology, Institute of Experimental Medicine, Budapest, Hungary \\ ${ }^{\mathrm{b}}$ Laboratory of Molecular Neuroendocrinology, Institute of Experimental Medicine, Budapest, Hungary \\ c Biological Research Center, Hungarian Academy of Sciences, Szeged, Hungary
}

\section{H I G H L I G H T S}

- AVP deficient Brattleboro rat strain is a valuable model to study schizophrenia.

- Lack of AVP resulted in changes of histone acetylation in the frontal brain and hippocampus.

- Influencing histone acetylation may provide therapeutic alternatives for schizophrenia.

\section{A R T I C L E I N F O}

\section{Article history:}

Received 14 September 2015

Received in revised form 4 December 2015

Accepted 9 December 2015

Available online 15 December 2015

Keywords:

Schizophrenia

Epigenetics

Vasopressin

Brattleboro

\begin{abstract}
A B S T R A C T
Schizophrenia-like symptoms were detected in vasopressin-deficient (di/di) Brattleboro rats, and it was also suggested that schizophrenia might have an epigenetic component. We aimed to clarify if epigenetic changes contribute to schizophrenia-like behavior of this strain.

Behavioral (locomotion by telemetry, cognition by novel object recognition, social recognition and social avoidance test, attention by pre-pulse inhibition) and epigenetic differences were compared between wild type and di/di animals. DNA methyltransferase1 (DNMT1), DNMT3a, as well as COMT, GAD, VGLUT1, 5HT2A, BDNF mRNA levels in prefrontal brain region and hippocampus were studied by qRT-PCR. Histone3 (H3) and $\mathrm{H} 4$ acetylation (Ac) were studied by western-blot followed by region specific examination of $\mathrm{H} 3$ lysine9 (K9) acetylation by immunohistochemistry.

Impaired cognitive, social and attention behavior of di/di rats confirmed schizophrenia-like symptoms in our local colony. The pan-AcH3 immunoreactivity was lower in prefrontal region and elevated in the hippocampus of di/di animals. We found lower immunopositive cell number in the dorsal peduncular prefrontal cortex and the ventral lateral septum and increased AcH3K9 immunoreactivity in CA1 region of di/di animals. There were no major significant alterations in the studied mRNA levels.

We confirmed that Brattleboro rat is a good preclinical model of schizophrenia. Its schizophrenialike behavioral alteration was accompanied by changes in $\mathrm{H} 3$ acetylation in the prefrontal region and hippocampus. This may contribute to disturbances of many schizophrenia-related substances leading to development of schizophrenia-like symptoms. Our studies confirmed that not a single gene, rather fine changes in an array of molecules are responsible for the majority of schizophrenia cases.
\end{abstract}

(c) 2015 Elsevier B.V. All rights reserved.

\section{Introduction}

Schizophrenia (SCZ), one of the major psychoses, affects more than $1 \%$ of the whole human population $[1,2]$. SCZ patients are char-

\footnotetext{
* Corresponding author at: Hungarian Academy of Sciences, Institute of Experimental Medicine, Department of Behavioral Neurobiology, H-1083 Budapest, Szigony utca 43, Hungary. Fax: +3612109954.

E-mail address: zelena.dora@koki.mta.hu (D. Zelena).

1 These authors contributed equally.
}

acterized by delusions, hallucinations, disorganized speech and behavior etc. [3]. These symptoms also include social dysfunction, which additionally affects family members and burden the society. Despite the importance, there is no cure for SCZ. Many partially effective therapies exist, but none can guarantee a cure to a specific case of the disease. The mechanism of all recently available antipsychotic drugs was discovered 60 years ago [4,5], their main therapeutic effect is the blockade of dopaminergic receptors [6]. A fundamental barrier to new drug development for the treatment of major psychiatric disorders was and still is an incomplete 
understanding of the ethiopathogenetic mechanisms underlying the symptomatology of these diseases.

The epigenetic hypothesis provides an integrative theory for SCZ [7-9] unifying the multifactorial origin under a common framework [10,11]. Genetic studies have linked many genes and chromosomal regions distributed throughout the genome to SCZ, but no single or small number of genes accounts for the majority of cases $[6,12]$. According to the biopsychosocial model of Engel perinatal development is a determining factor for later occurrence of psychiatric disorders [13]. Especially during this period (but also later in life) environmentally induced epigenetic changes may activate (e.g., histone acetylation by acetyltransferase (HAT)) or inhibit (e.g., DNA methylation by DNA methyltransferases (DNMT) or histone deacetylation by deacetylases (HDAC)) the expression of different genes [14,15]. Therefore on the same genetic background different susceptibility to SCZ-inducing life events may develop [16]. As developmental disturbances are core features of SCZ, and epigenetic changes occur globally in early development acting as interface between the environment and the genome [17], we might assume that epigenetic rather than genetic changes have general ethiopathogenic role. Indeed, the first suggestion on the epigenetic aspect of SCZ goes back to the early 60s, when enhancing DNA methylation by methionine administration was shown to exacerbate psychotic symptoms [18]. Since then many studies found epigenetic modifications in SCZ patients, as well as in animal models (for a review see e.g., our book chapter [14]). The importance of epigenetic theory is that epigenetic processes are highly dynamic unlike the DNA sequence of a cell, which is stable and strongly conserved. Therefore epigenetic disruptions may develop relatively fast and are potentially reversible, thus a realistic target for pharmacological intervention. Indeed, the fact that antipsychotics are clinically effective just after prolonged treatment, and-similarly-more time is needed for the development of epigenetic changes, suggests that one of the main target of these drugs might be the epigenome [19-21].

Development of new drugs requires animal models. Genetic models have the advantage that the SCZ-inducing intervention does not interfere with the treatment drug. However, one might assume that the perinatal development of these animals is similarly important leading to epigenetic changes on a disturbed genetic background. Here we were focusing on the arginine vasopressin (AVP) deficient (di/di) Brattleboro rat strain. Reduced level of this social hormone [22-26], or its carrier, neurophysin [24] was found in SCZ patients. Later studies revealed an association between AVP gene [27] or AVP 1a receptor [28,29] and some behavioral dysfunction (e.g., pre-pulse inhibition (PPI)). Moreover, some of the SCZ-symptoms were ameliorated by treatment with AVP analogs [30-35]. However, other studies found elevated levels [36,37] or no beneficial effect of the AVP treatment [38], therefore direct pathogenic role of AVP-deficiency in the development of symptoms is not evident.

Nevertheless, the AVP-deficient Brattleboro rat shows SCZrelated symptoms, which develop spontaneously. This strain, in addition to exhibiting a diabetes insipidus-like phenotype characterized by polydipsia and polyuria, have been shown to have a number of cognitive and behavioral abnormalities that are analogous to those seen in SCZ patients, including abnormalities in memory, emotional reactivity, social recognition, motivation and attention [39-44]. As AVP is not clearly connected to disease etiology, epigenetic contribution is more likely leading to secondary changes in different neurotransmitter systems [45,46].

We hypothesized, that epigenetic changes as some particular DNA and histone modifications, may contribute to the development of SCZ-like symptoms in this animal model. We focused on the frontal part of the brain (FB) as the main area thought to be involved in SCZ [47] and associated mostly with epigenetic changes in this disorder $[14,48,49]$. However, the current literature does suggest that alterations are not isolated to a few brain regions, but are characterized by abnormalities within brain networks [50], like the hippocampo-prefrontal cortex (PFC) system [51]. Thus, we studied the hippocampus (HC) as well, as one of the main center of memory [52], because cognitive deficits are most predictive of long-term outcomes of SCZ. According to recent findings cortical GABAergic deficit dominates SCZ pathophysiology [53], therefore we examined its detection marker, the synthetizing enzyme glutamate decarboxylase (GAD1), the isoform known to be downregulated in PFC [54] and HC [55] of SCZ patients. In relation with the dopaminergic, glutamatergic and serotonergic neurotransmitter systems, cathecol-o-methy-transferase (COMT), vesicular glutamate transporter1 (VGLUT1) and 5HT2A receptor mRNA levels were studied respectively. Neurodevelopmental changes were examined by changes in brain derived neurotrophic factor (BDNF) mRNA. Methylation changes of these special genes were observed mostly in relation to SCZ [14].

\section{Materials and methods}

\subsection{Animals}

Adult, male Brattleboro rats ( $330 \mathrm{~g}, 10-12$ weeks old) were maintained in our institute [56] in a colony started from breeder rats from Harlan, Indianapolis, IN, USA. Rats were kept in conventional plastic cages $(30 \times 40 \mathrm{~cm})$ among controlled environment $\left(23 \pm 1{ }^{\circ} \mathrm{C}, 50-70 \%\right.$ humidity, $12 \mathrm{~h}$ light starting at 07:00 h) and given commercial rat chow (Charles River, Budapest, Hungary) and tap water ad libitum. We compared the AVP deficient homozygous (di/di) rats with diabetes insipidus to homozygous normal $(+/+)$ control rats. All experiments were conducted in the morning between 09:00 and 12:00 h. The experiments were performed in accordance with regulations set by the European Communities Council Directive (2010/63/EU) and were approved by our Institutional Animal Care and Use Committee.

\subsection{Biotelemetry}

Locomotor activity was monitored via implanted biotelemetry emitters (Minimitter Co., Bend, OR, USA) as described earlier [57]. In brief, the emitter was placed into the abdominal cavity of rats through a midline abdominal incision under Ketamin $(50 \mathrm{mg} / \mathrm{kg}$; Produlab Pharma b.v., Netherlands), Xylasine $(10 \mathrm{mg} / \mathrm{kg}$; Produlab Pharma b.v., Netherlands), and Pipolphen ( $5 \mathrm{mg} / \mathrm{kg}$; Egis Pharmaceuticals PLC, Hungary) anesthesia. Biotelemetric recordings started 2 weeks later and were made by means of a 12-channel VitalView system (Minimitter Co.). Daily activity was monitored for $24 \mathrm{~h}$, started in the first hour of dark period, visualized in Zeitgeber time.

\subsection{Behavioral tests}

\subsubsection{Novel object recognition test (NOR)}

The rats were singly habituated to the experimental cages $(41.3 \times 26 \times 29.8 \mathrm{~cm}$, GeoMaxi, Ferplast, Italy) with fresh bedding $1 \mathrm{~h}$ before starting the test. For the object related equivalent of social discrimination we developed an experimental design comparable to the social paradigm in both time course and test settings [58]. Two different objects were used: a $62 \mathrm{~g}$ tin box and an $80 \mathrm{~g}$ bottle of tomato sauce. One of this objects (Object 1) was presented for $4 \mathrm{~min}$ (sampling phase), than removed, and 30 min later the same (Object 1) and a different object (Object 2) were introduced to the rat for $4 \mathrm{~min}$. The objects were thoroughly cleaned with alcohol before each animal. The tests were videotaped and 
analyzed later by an experimenter blind to the treatments by means of a computer-based event recorder (H77, Budapest, Hungary). In behavior directed toward the object we distinguished sniffing and gnawing as an important component. To exclude object preference the two objects were randomly used as Object 1 or Object 2. Discrimination index was calculated as follows: (time percentage Object 2 - time percentage Object 1 )/(time percentage Object $1+$ time percentage Object 2$) \times 100$. The result of the index changes between $-100 \%$ and $+100 \%$, where $0=$ no discrimination. Normally the animals spend more time with the new stimulus (novelty effect), thus the index around or below 0 is a sign of memory deficit.

\subsubsection{Social recognition test (SR)}

Like in the NOR test, after the habituation period, instead of the objects, a juvenile rat (average 20 days old) was placed into the cage for $4 \mathrm{~min}$ (sampling phase) [59]. After a 30-min inter-trial interval the juvenile from trial 1 (old) plus a novel juvenile were placed there for $4 \mathrm{~min}$ (juveniles were marked with different colors). Both $4 \mathrm{~min}$ were video-recorded and later the amount of interaction was measured. The first session shows social interaction tendency in a novel environment and the second one shows the discrimination capability between the two juveniles. Discrimination index was calculated as above in NOR.

\subsubsection{Social avoidance (SA)}

The test was performed as described earlier [57]. Briefly, rats were studied in two plastic cages connected by a sliding door. The subject was placed in the smaller cage (surface: $15 \mathrm{~cm} \times 50 \mathrm{~cm} \times 40 \mathrm{~cm}$ ) for a $3 \mathrm{~min}$ habituation period. The larger cage $(40 \mathrm{~cm} \times 40 \mathrm{~cm} \times 40 \mathrm{~cm})$ was divided into two equal compartments by a transparent, perforated plastic wall. The distant compartment contained a large unfamiliar male. After the habituation period, the sliding door was removed, and the subject was allowed to explore the cage for $5 \mathrm{~min}$. The test apparatus did not permit physical contact between the experimental and stimulus animals. Behavior was video-recorded from above and analyzed later. Three variables were recorded: the frequency of visits made to the compartment containing the opponent as well as duration and the interaction with unfamiliar male (opponent entries and time\% spent with opponent, respectively).

\subsubsection{Prepulse inhibition (PPI)}

The Colbourne Instruments (USA) Acoustic Startle setup was used in our experiments. After a weight calibration subjects were placed in a test cage on an instrument measuring the startle response (by recording small changes in weight) inside a sound attenuated chamber. Following $5 \mathrm{~min}$ of habituation subjects were presented $40 \mathrm{~ms}$ long, $120 \mathrm{~dB}$ acoustic stimuli (noise) for 5 times in every $20 \mathrm{sec}$ to standardize startle. Five trial types were then presented during testing: (i) $40 \mathrm{~ms}$ long $120 \mathrm{~dB}$ startle pulse without prepulse, (ii-iv) $40 \mathrm{~ms} 120 \mathrm{~dB}$ pulse preceded $80 \mathrm{~ms}$ by a $20 \mathrm{~ms}$ prepulse (tone) of three varying intensity $(73,77$ or $81 \mathrm{~dB}$ ) and (v) a trial with no prepulse and $0 \mathrm{~dB}$ pulse. Trials were repeated until every type of trials was presented 5 times. Different animals received different trial types in a different, randomized order. Immediately afterwards other four trial types were randomly applied with $75 \mathrm{~dB}$ prepulse and increasing intervals $(30,100,300$ and $500 \mathrm{~ms}$ ) between pre-pulse and pulse (ISI). The program automatically recorded the startle response. Response to the $0 \mathrm{~dB}$ pulse was the weight of the subject and was subtracted from subsequent startle response data. Mean of the startle response to the $120 \mathrm{~dB}$ pulse without prepulse was calculated for every subjects and considered $100 \%$, from which prepulse inhibition (PPI) was calculated by the following formula: PPI = $100-($ (startle after prepulse $/$ startle without prepulse $) \times 100$ ). Mean PPI values were given for different prepulse intensities.

\subsection{Polymerase chain reaction $(P C R)$}

After decapitation brains were quickly removed, whole FB (rostral part of the brain from Bregma $0 \mathrm{~mm}$ ) and dorsal HC were hand-dissected and flash-frozen in dry ice, put in a sterile nuclease free plastic tube and kept on $-80^{\circ} \mathrm{C}$ until processing. Frozen tissue samples were homogenized in TRI Reagent Solution (Ambion, USA) and total RNA was isolated with QIAGEN RNeasy Mini Kit (Qiagen, Valencia, CA, USA) according the manufacturer's instruction. To eliminate genomic DNA contamination DNase I treatment were used and $100 \mu$ l RNase-free DNase I ( 1 unit DNase) (Thermo Scientific, USA) solution was added. Sample quality control and the quantitative analysis were carried out by NanoDrop (Thermo Scientific, USA). Amplification was not detected in the RT-minus controls. The cDNA synthesis was performed with the High Capacity cDNA Reverse Transcription Kit (Applied Biosystems, USA). Primers for the comparative $\mathrm{Ct}$ experiments were designed by Primer Express 3.0 Program. Glyceraldehyde 3-phosphate dehydrogenase (GAPDH) was used as housekeeping gene.The DNMT1, GAD1, catechol-O-methyltransferase (COMT), vesicular glutamate transporter-1 (VGLUT1, SLC17A7 gene), serotonin receptor subtype 2A (5HT2A), brain-derived neurotrophic factor (BDNF) and GAPDH primers (Microsynth, Switzerland) were used in the Real-Time PCR reaction with Fast EvaGreen ${ }^{\circledR}$ qPCR Master Mix (Biotium, USA), while DNMT3a (Rn01027162_g1, Life Technologies) and GAPDH (Rn01775763_g1, Life Technologies) by Light Cycler 480 Probes Master (Roche) on ABI StepOnePlus instrument. The following primer pairs were designed:

DNMT1 forward: AGCATTCCCGTACAGAGCAG

reverse: CGGGTTGAGCTTTGGGATTG

GAD1 forward: TGAATCGAGCCCGTTCCTG

reverse: GGCTACGCCACACCAAGTAT

COMT forward: CGTGTTAAAACCCGTGTCTGC

reverse: AGCCAACGGCATCTCCTCAA

VGLUT1 forward: CCACGACCAATGTGCGAAAG

reverse: GAGTATCCGACCACCAGCAG

5HT2A forward: AGCTGATATGCTGCTGGGTTT

reverse: CACCGGTACCCATACAGGA

BDNF forward: AAACGTCCACGGACAAGGCA

reverse: TTCTGGTCCTCATCCAGCAGC

GAPDH forward: ACAGCCGCATCTTCTTGTGC

reverse: GCCTCACCCCATTTGATGTT

\subsection{Western blot}

Brain were handled as in case of PCR and the frozen tissues were homogenized in $200 \mu$ l of ice-cold extraction buffer containing $250 \mathrm{mM}$ sucrose, $50 \mathrm{mM}$ Tris, pH 7.5, $25 \mathrm{mM} \mathrm{KCl}, 0.5 \mathrm{mM}$ PMSF, $0.9 \mathrm{mM} \mathrm{NaB}$, as well as protease inhibitors (protease inhibitor cocktail, Roche, Basel, Switzerland) and phosphatase inhibitors (phosphatase inhibitor cocktail 1, Sigma). The nuclear fraction (pellet) was separated by centrifugation at $7700 \times g$ for $1 \mathrm{~min}\left(4^{\circ} \mathrm{C}\right)$, and re-suspended in $1 \mathrm{ml} 0.4 \mathrm{~N} \mathrm{H}_{2} \mathrm{SO}_{4}$ and incubated for $30 \mathrm{~min}$ $\left(4^{\circ} \mathrm{C}\right)$. Samples were centrifuged at $14,000 \times \mathrm{g}$ for $30 \mathrm{~min}\left(4^{\circ} \mathrm{C}\right)$. $250 \mu \mathrm{l}$ trichloroacetic acid (with $4 \mathrm{mg} / \mathrm{ml}$ deoxycholate) was added to the supernatant, and incubated for $30 \mathrm{~min}\left(4^{\circ} \mathrm{C}\right)$ to precipitate protein. Samples were then spun at $14,000 \times \mathrm{g}$ for $30 \mathrm{~min}\left(4^{\circ} \mathrm{C}\right)$ to pellet protein. Pellets were washed for $5 \mathrm{~min}$ with $1 \mathrm{ml}$ acidified acetone $(0.1 \% \mathrm{HCl})$, then for $5 \mathrm{~min}$ with acetone. Between washes, protein was collected by centrifuging $5 \mathrm{~min}$ at $14,000 \times \mathrm{g}\left(4^{\circ} \mathrm{C}\right)$, and aspirating supernatant. After the last wash, the pellet was resuspended in $200 \mu \mathrm{l} 10 \mathrm{mM}$ Tris, $\mathrm{pH} 8.0$, and incubated for $15 \mathrm{~min}$ at room temperature. Protein concentrations were determined using 
a Nanodrop. Equivalent amounts of protein $(10 \mu \mathrm{g})$ for each sample were resolved with SDS-PAGE using 4-15\% gradient Tris- $\mathrm{HCl}$ gels. After electrophoresis, proteins were transferred to nitrocellulose membranes for $2 \mathrm{~h}$ at $50 \mathrm{~V}$. Membranes were incubated in blocking buffer (LI-COR, Lincoln, Nebraska, USA) $1 \mathrm{~h}$ at room temperature to block non-specific binding. The blots were reacted with primary antibodies (H3, ab1791, Abcam; AcH4K8, ab15823, Abcam, AcH4K12, 07-595, Millipore, 1:5000; H4, ab10158, Abcam, 1:10,000 and $\mathrm{AcH} 3,06-599$, Millipore, 1:20,000) overnight at $4{ }^{\circ} \mathrm{C}$, then immunolabeled by chemiluminescence and followed by detection with ChemiDoc ${ }^{\mathrm{TM}}$ XRS+ System with Image Lab ${ }^{\mathrm{TM}}$ Software. The $\mathrm{AcH} 3 / \mathrm{H} 3$ bands were detected at $17 \mathrm{kDa}$ and the $\mathrm{AcH} 4$ band was detected at $10 \mathrm{kDa}$. As there was no appropriate pan-AcH4 antibody available, we measured two specific $\mathrm{H} 4$ acetylation site, the lysine acetylation at $8(\mathrm{AcH} 4 \mathrm{~K} 8)$ or $12(\mathrm{AcH} 4 \mathrm{~K} 12)$ position. Ratios of $\mathrm{AcH} 3$ or $\mathrm{AcH} 4$ to total $\mathrm{H} 3$ or $\mathrm{H} 4$ were calculated for each sample and analyzed across conditions.

\subsection{Immunohistochemistry (IHC)}

Rats, who underwent PPI, were deeply anesthetized by a mixture described by biotelemetry and trans-cardially perfused with $100 \mathrm{ml}$ saline followed by $300 \mathrm{ml}$ ice cold $4 \%(\mathrm{w} / \mathrm{v})$ paraformaldehyde (PFA; Molar Chemicals Ltd., Hungary) in phosphate buffered saline (PBS). Aorta descendens was pinched by pean forceps. The brains were removed from the skull, post-fixed for 1 day in PFA at $4{ }^{\circ} \mathrm{C}$ and cryoprotected in $30 \%$ glucose (w/v in PBS) containing $0.1 \%(w / v)$ sodium-azide (Sigma-Aldrich, Inc., Hungary). Six series of $30 \mu \mathrm{m}$ frozen sections were cut in the frontal plane on a sliding microtome. Floating sections were incubated in PBS containing $0.5 \%$ Triton $\mathrm{X}-100$ and $0.5 \% \mathrm{H}_{2} \mathrm{O}_{2}$ for $30 \mathrm{~min}$. Non-specific antigens were blocked by $2 \%$ bovine serum albumin (BSA; Sigma-Aldrich) in PBS for $30 \mathrm{~min}$ at room temperature. Sections were incubated for $72 \mathrm{~h}$ at $4{ }^{\circ} \mathrm{C}$ with anti-histone $\mathrm{H} 3$ (Acetyl-Lys9) antibody made in rabbit (1:5000, SAB4500347 Sigma-Aldrich, Inc., Hungary), diluted in blocking solution. After thorough PBS washing sections were incubated for $1 \mathrm{~h}$ in biotinylated anti-rabbit IgG secondary antibody (1:500) (Vector Laboratories). Next, sections were incubated in avidin-biotin complex $(1: 1000)$ (ABC Vectastain Elite kit, Vector Laboratories) diluted in $0.05 \mathrm{M}$ Tris buffered saline (TBS, $\mathrm{pH}$ 7.6) for $1 \mathrm{~h}$ at room temperature. H3K9ac immuno-positive cells were visualized by nickel enhanced 3,3'-diaminobenzidine (DAB). Sections were incubated for equal time in Tris-buffered solution containing $0.2 \mathrm{mg} / \mathrm{ml} \mathrm{DAB}, 0.1 \%$ nickel-ammonium-sulphate and $0.003 \% \mathrm{H}_{2} \mathrm{O}_{2}$. Enzymatic reaction was stopped by thorough TBS washing. Sections were mounted on glass slides in chromegelatin solution $[0.5 \%(\mathrm{w} / \mathrm{v})$ gelatin (Sigma-Aldrich) and $1 \mathrm{mM}$ Chromium(III) potassium sulfate dodecahydrate (Sigma-Aldrich)], dehydrated by mixtures of xylol isomers and covered by DPX mounting medium (Sigma-Aldrich, Inc., Hungary). Microscopic images were digitized by OLYMPUS CCD camera, and stained particles were counted by means of the ScionImage software. The methods of quantification of immune-positive cells see in Ref. [60].

\subsection{Statistical analysis}

Data were analyzed by analysis of variance (ANOVA) using the STATISTICA 12 software package (Tulsa, OK, USA). One (factor genotype) or repeated measure (factor genotype and time or new-old, or latency) ANOVA was conducted. For post-hoc analysis Newman-Keuls test was used. We have analyzed the correlation between immunohistochemical and PPI data by Pearson correlation. Data were expressed as mean \pm SEM and the level of significance was set at $p<0.05$.

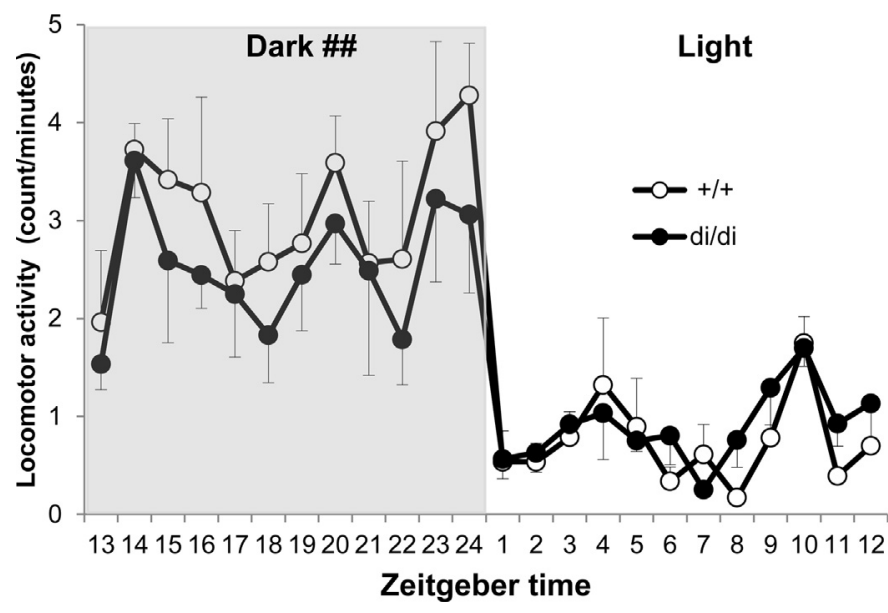

Fig. 1. Daily locomotor activity (counts/minutes in each hour) was monitored in vasopressin-deficient ( $\mathrm{di} / \mathrm{di}$ ) Brattleboro rats for $24 \mathrm{~h}$ by biotelemetric equipment Measurement was started in the 1 st hour of dark period. No significant differences were observed between $+/+$ and di/di animals. Both genotypes follow the normal circadian rhythm. Grey background denotes the dark period. \#\#p $<0.01$ vs. light period.

\section{Results}

\subsection{Locomotor activity}

The telemetric data did not show any significant differences between the genotypes at any studied timepoint of the day (Fig. 1). The locomotor activity followed the normal lifecycles, thus, both genotypes were significantly more active during the dark phase than in light $\left(F_{\text {time }}(23,115)=10.00 ; p<0.01\right)$. The genotype did not influence this circadian variation (no genotype $\times$ time interaction).

\subsection{Novel object recognition test}

In the sampling phase of NOR $+/+$ and di/di animals spent same time with the Object 1 (old) (Fig. 2A). During the test phase (Fig. 2B) repeated measure ANOVA showed a significant difference between the time spent sniffing the new and the old object $\left(F_{\text {new-old }(1,14)}=4.73 ; p<0.05\right)$ with a tendency of its interaction with the genotype $\left(F_{\text {new-old } \times \text { genotype }(1,14)}=4.24 ; p=0.059\right)$. Post-hoc analysis showed that during the test phase di/di animals spent same time with old and new object, while $+/+$ rats sniffed more the new one $(p<0.01)$. Furthermore, $+/+$ and di/di animals spent almost similar time with the new object, but di/di rats explored significantly more time the old one than the $+/+(p<0.05)$. The calculated discrimination index showed that di/di rats had significantly weaker ability to distinguish new from old object $\left(F_{\text {genotype }(1,14)}=11.52\right.$; $p<0.01$ ) (Fig. 2C).

\subsection{Social recognition test}

Similarly to NOR, in the sampling phase of SR $+/+$ and di/di animals interacted the same time with the Animal 1 (old) (Fig. 2D). Repeated measure ANOVA showed a significant difference between the time spent sniffing the new and the old juvenile $\left(F_{\text {new-old }(1,11)}=21.61 ; p<0.01\right)$, which was detectable only in $+/+$ animals $\left(F_{\text {new-old } \times \text { genotype }(1,11)}=8.01 ; p<0.05\right)$. Post-hoc analysis showed that during the test phase di/di animals spent the same time with old than with new juvenile, while $+/+$ rats interact more with the new one $(p<0.01)$ (Fig. 2E). Discrimination index revealed that di/di rats had significantly weaker ability to distinguish old animal from the new $\left(F_{\text {genotype }(1,11)}=14.17 ; p<0.01\right)$ (Fig. $\left.2 \mathrm{~F}\right)$. 
A

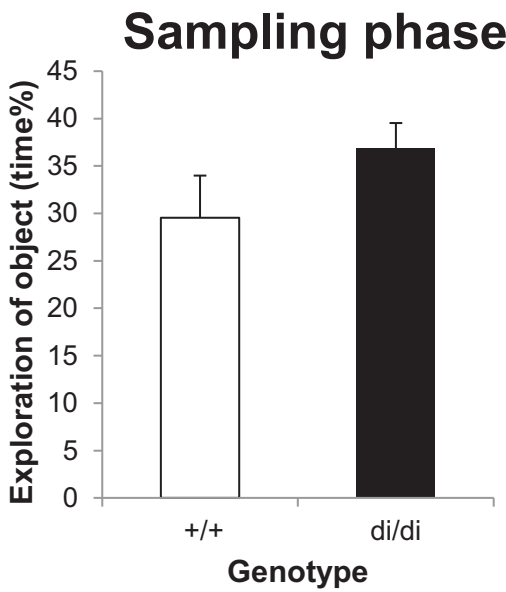

B

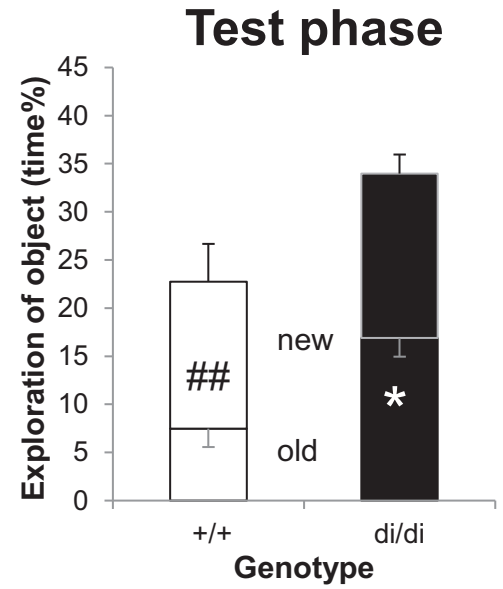

C

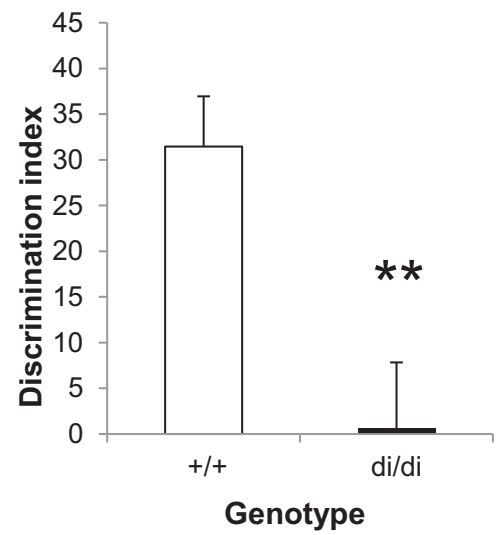

Sampling phase

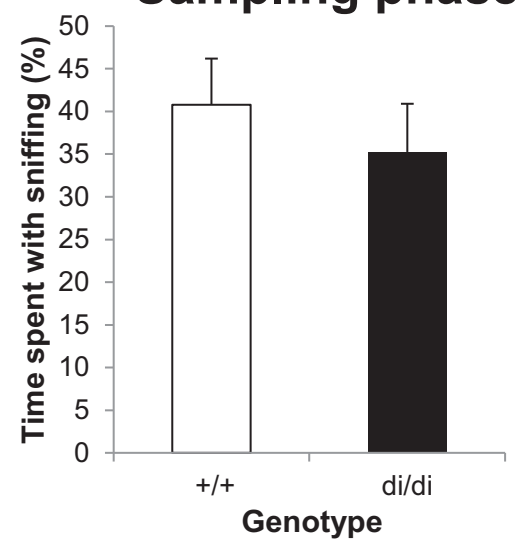

$E$
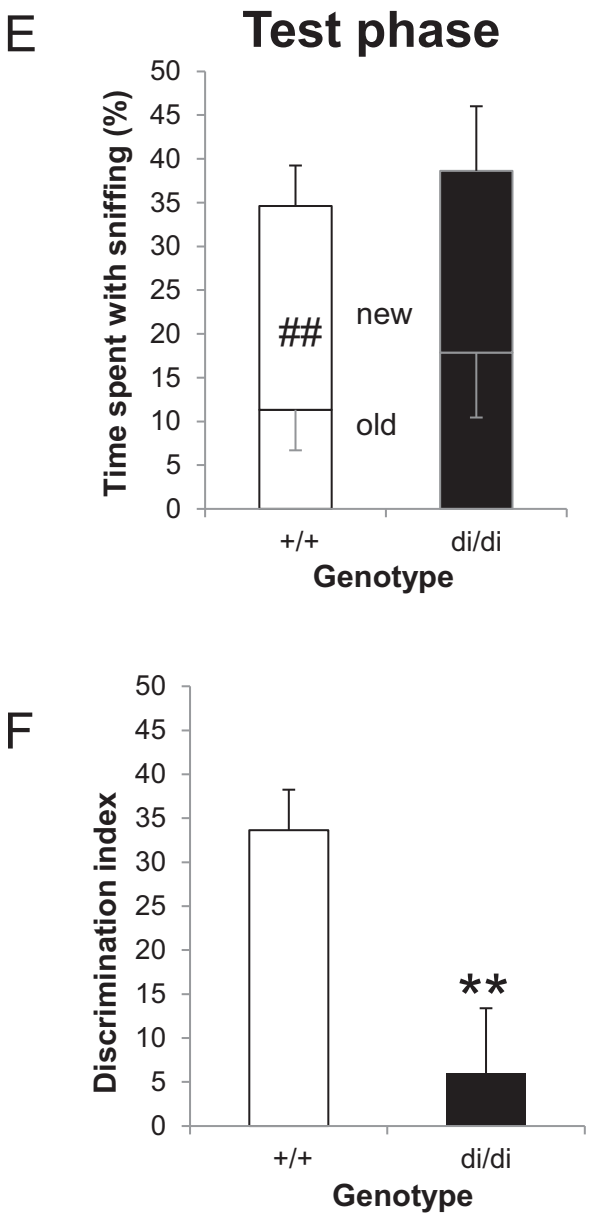

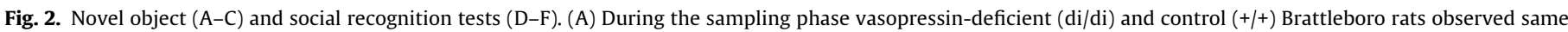

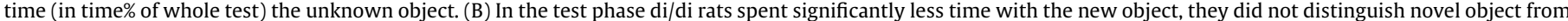

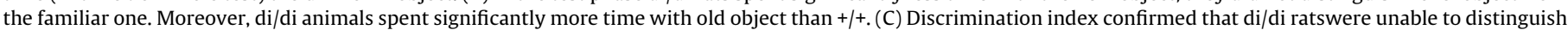

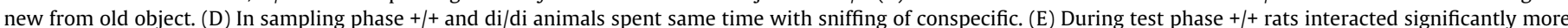

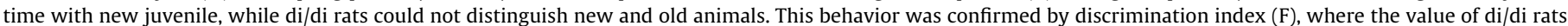
was close to 0 . \#\#p $<0.01$ time\% sniffing new vs. old object (B) or old juvenile (E); ${ }^{*} p<0.05,{ }^{* *} p<0.01$ genotype difference.

\subsection{Social avoidance test}

The AVP-deficient di/di rats enter less frequently $\left(F_{\text {genotype }(1,13)}=5.55 ; \quad p<0.05\right) \quad($ Fig. $3 \mathrm{~A})$, spent less time $\left(F_{\text {genotype }(1,13)}=5.10 ; \quad p<0.05\right)$ in the large compartment (Fig. 3B) and sniffed significantly less the unfamiliar male $\left(F_{\text {genotype }(1,13)}=4.69 ; p<0.05\right)$ than their $+/+$ counterpairs.

\subsection{Prepulse inhibition test}

Prepulse inhibition was less effective in di/di rats compared with $+/+$ animals, especially at lower prepulse intensity level $(73 \mathrm{~dB}$ : $F_{\text {genotype }(1,18)}=7.10 ; p<0.05,77 \mathrm{~dB}: F_{\text {genotype }(1,18)}=2.44 ; p=0.14$, $81 \mathrm{~dB}: F_{\text {genotype(1.18) }}=4.18 ; p=0.06$ ) (Fig. $3 \mathrm{C}$ ). We investigated the effect of increasing inter-stimulus interval (ISI) at $75 \mathrm{~dB}$ prepulse 
A
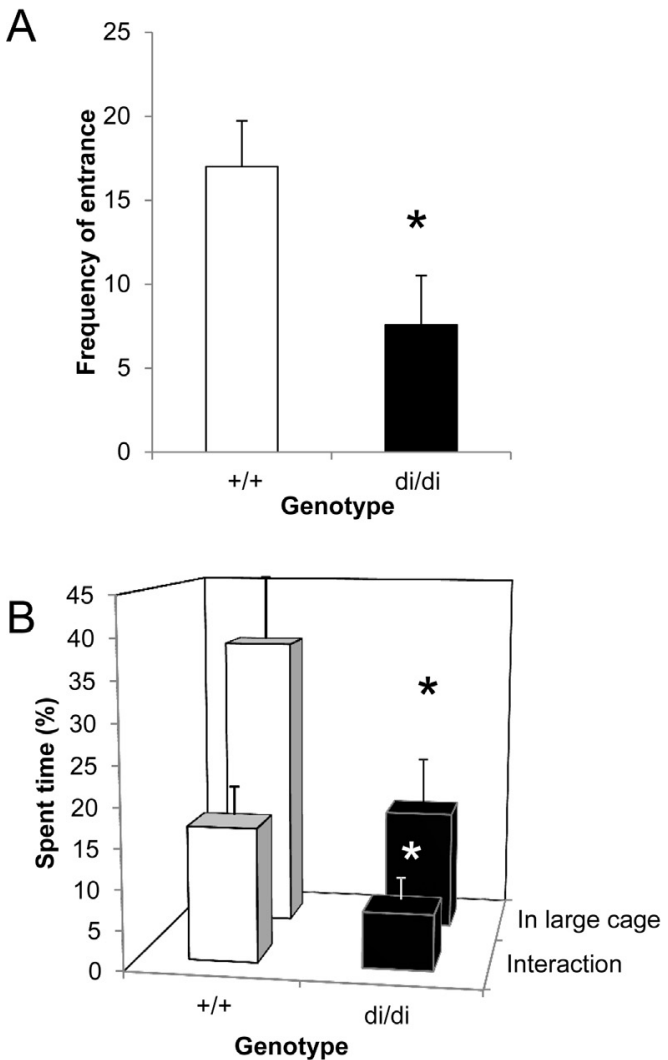
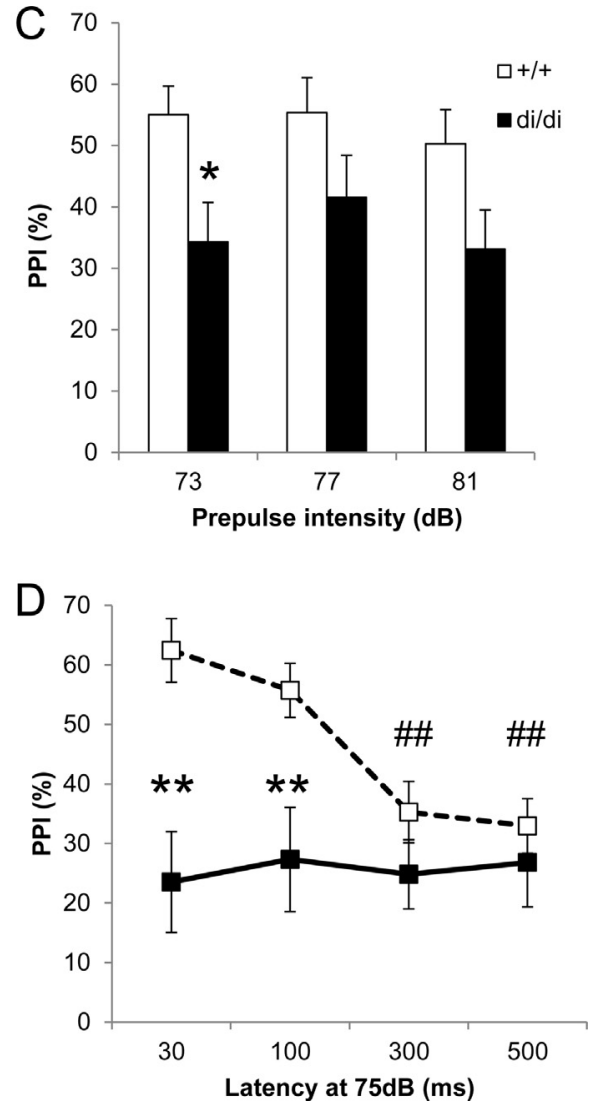

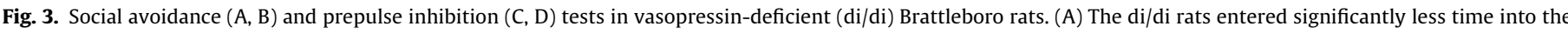

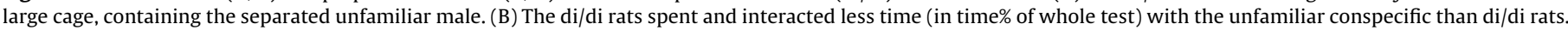

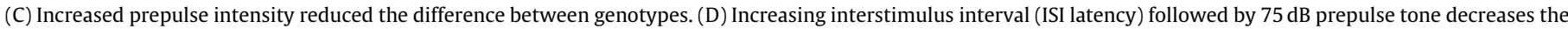
inhibition in $+/+$ rats, while did not change the PPI in di/di rats. ${ }^{*} p<0.05,{ }^{* *} p<0.01$ genotype difference. \#\#p $<0.01 \mathrm{vs.} 30 \mathrm{~ms}$ ISI latency.

and $120 \mathrm{~dB}$ pulse on PPI (Fig. 3D). The response of $+/+$ rats at increasing latency inversely correlated with PPI. There were significant differences between genotypes $\left(F_{\text {genotype }(1,17)}=9.76 ; p<0.01\right)$ as the PPI of di/di rats did not react to changes in ITI. It was reflected also by a significant interaction between ISI and genotype $\left(F_{\text {ISI } \times \text { genotype(3,51) }}=4.25 ; p<0.01\right)$. Post-hoc analysis showed a significant decrease of PPI in $+/+$ rats, when we compared the $30 \mathrm{~ms}$ ISI with $300 \mathrm{~ms}$ and $500 \mathrm{~ms}$ latency ( $p<0.01$ both cases). Moreover, the genotype difference disappeared at 300 and $500 \mathrm{~ms}$ latencies.

\section{6. $q R T-P C R$}

Fold changes of expression of dnmt1, dnmt3a, gad1, comt, vglut1, $5 h t 2 a$ and bdnf genes were investigated in FB and in HC, correlated to $+/+$ animals (Fig. 4A and B). DNMT1 in the frontal area showed significantly lower level in di/di rats $\left(F_{\text {genotype }}(1,10)=8.71 ; p<0.05\right)$, while in the HC and the other 6 gene transcript in both investigated area, showed no significant differences.

\subsection{Western blot}

In the $\mathrm{FB}$ of di/di rats the pan- $\mathrm{AcH} 3 / \mathrm{H} 4$ ratio was significantly lower than in $+/+$ ones $\left(F_{\text {genotype }(1,7)}=7.32 ; p<0.05\right)$ (Fig. $\left.4 \mathrm{C}\right)$. On the other hand, in the $\mathrm{HC}$ this pan- $\mathrm{AcH} 3 / \mathrm{H} 4$ ratio was much higher in $\mathrm{di} /$ di rats than in $+/+$ ones $\left(F_{\text {genotype }(1,12)}=23.87 ; p<0.01\right)$. AcH4K12 and $\mathrm{AcH} 4 \mathrm{~K} 8$ ratio compared to $\mathrm{H} 3$ did not show significant differences neither in the FB nor in the HC.

\subsection{Immunohistochemistry}

The following brain regions were investigated (Fig. 5E): nucleus accumbens core (AcbC) and shell (AcbS) regions, prelimbic cortex (PrL), infralimbic cortex (IL) and dorsal peduncular cortex (DP), dorsal (LSD), intermediate (LSI) and ventral (LSV) part of the lateral septum, as well as CA1, CA2 and CA3 fields of the dorsalHC.

In the di/di animals AcH3K9 immunostaining showed significantly less labeled cells in the dorsal peduncular cortex (DP) of the PFC than in the $+/+$ rats $\left(F_{\text {genotype }(1,16)}=5.24 ; p<0.05\right)$ (Fig. $\left.5 A\right)$. In the other investigated PFC areas (PrLand IL) no differences were detected between the genotypes. AcH3K9 immunohistochemistry did not show significant differences between di/di and $+/+$ animals neither in the whole Acb nor in the separately investigated core and shell (Fig. 5B). In the lateral septum only in LSV compartment were significantly less AcH3K9 immunopositive cells in di/di than in $+/+$ rats $\left(F_{\text {genotype }(1,16)}=5.37 ; p<0.05\right)$ (Fig. $5 C$ ). In the CA1 there was significantly more AcH3K9 labeled cell in di/di rats than $+/+$ $\left(F_{\text {genotype }(1,15)}=5.81 ; p<0.05\right)$, while in CA2 and CA3 there was no genotype effect (Fig. 5D).

There was a negative correlation between the ISI parameter of PPI test and the number of AcH3K9 immunopositive cells in the CA1 (vs. $75 \mathrm{~dB} 100 \mathrm{~ms}$ ISI $r=-0.63, p<0.01$, vs. $75 \mathrm{~dB} 300 \mathrm{~ms}$ ISI $r=-0.50$, $p<0.05)$. Marginal negative correlation was measured between PFC and the $75 \mathrm{~dB} 300 \mathrm{~ms}$ ISI $(r=-0.44, p=0.078)$.

We had correlated the values of the investigated brain areas (see Table 1). There was a significant positive correlation between DP area and AcbC $(r=0.47, p<0.05)$, LSI $(r=0.48, p<0.05)$ and LSV 
RT-PCR
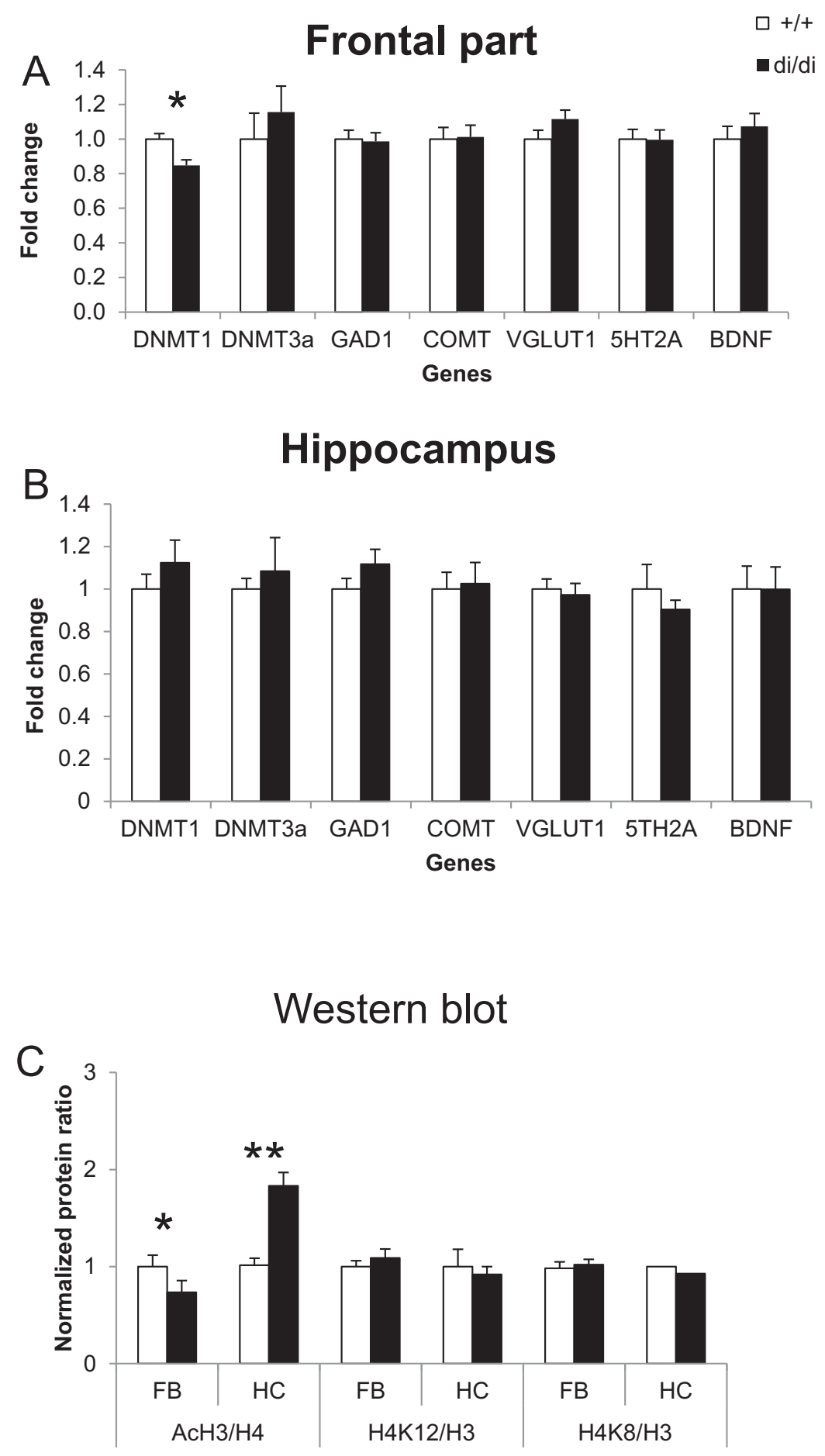

Histone ratio in brain area

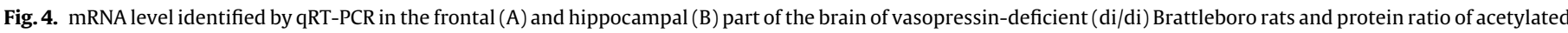

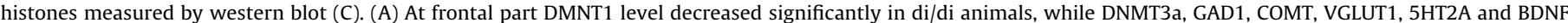

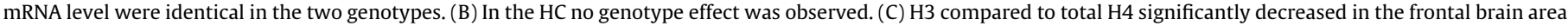

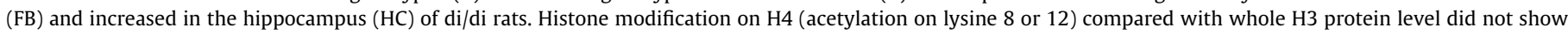
significant differences. ${ }^{*} p<0.05,{ }^{* *} p<0.01$ genotype difference.

$(r=0.55, p<0.05)$. The core region of the accumbens significantly correlated with CA3 $(r=0.61, p<0.05)$, while the shell region positively correlated with $\operatorname{LSD}(r=0.50, p<0.05)$, LSI $(r=0.70, p<0.01)$ and $\operatorname{LSV}(r=0.50, p<0.05)$.

\section{Discussion}

Combining behavioral studies with molecular biological techniques we demonstrated that in Brattleboro rat the lifelong 


\section{AcH3K9}

A

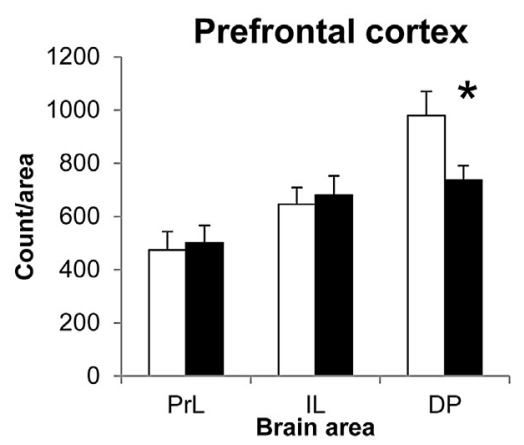

C

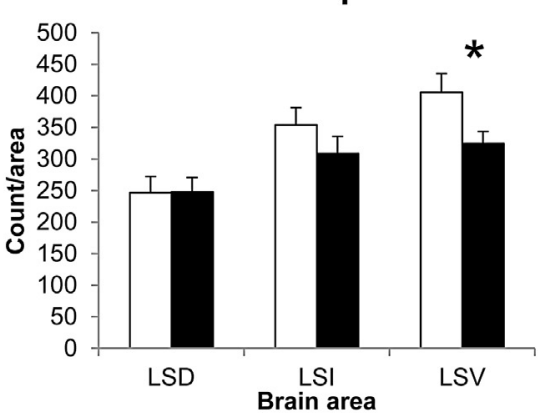

\section{B}

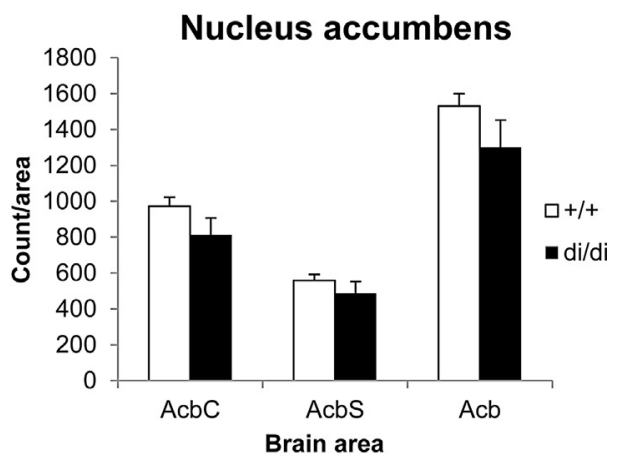

D

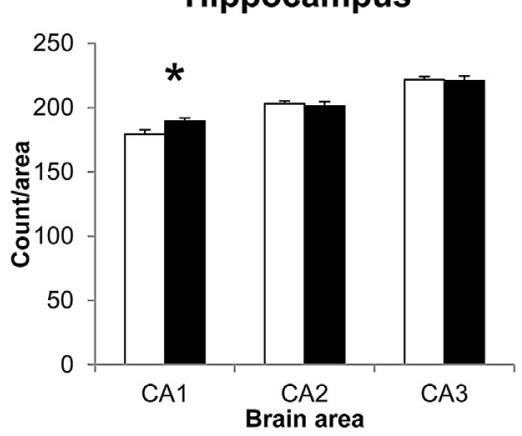

$\mathrm{E}$

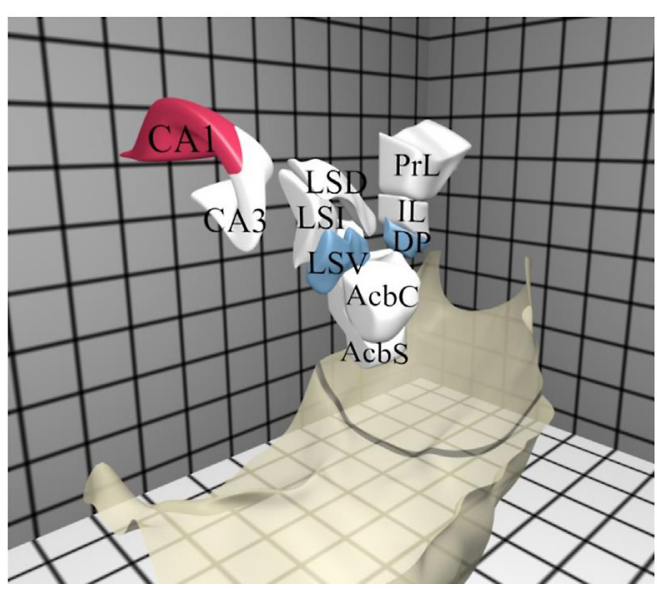

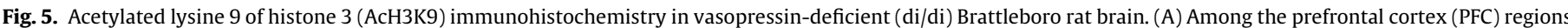

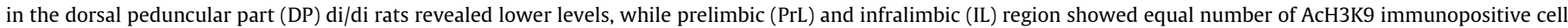

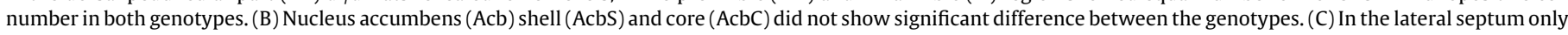

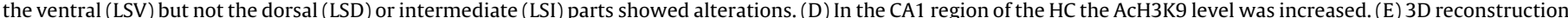

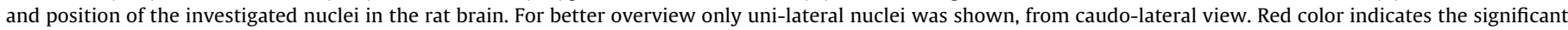

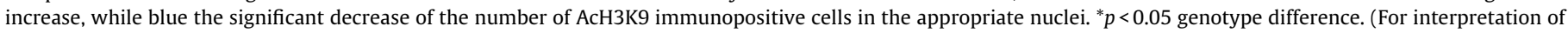
the references to color in this figure legend, the reader is referred to the web version of this article.)

frameshift mutation in the gene coding for the neuropeptide AVP resulted in epigenetic alteration in the frontal part of the brain (DP, LSV) and in the hippocampus (CA1), which can underline the appearance of SCZ-like behavior in Brattleboro rats.

Earlier observations (for references see introduction) and our recent study confirmed lots of similarities between SCZ patients and the SCZ-like behavior of di/di rats. However, previous work concentrated on a single test (mostly on PPI), but SCZ is a spectrum disorder, thus, we have to take into consideration a wide range of behaviors [61]. In this sense, our work is the first summary presenting in a single colony a wide range of SCZ-like behavior in the
Brattleboro rat from all domains (positive, negative and cognitive). Cognitive impairment has drawn attention as particularly important being one of the more treatment resistant components. In the present study cognitive symptoms were studied by NOR and SR, showing that our colony has SCZ-like deficiencies similarly to previous observations [42,58,62-64]. Another negative symptom, the lack of interest to conspecific was confirmed by SA test, which was never used in this strain before, although social impairment was already described in Brattleboro rat $[58,65,66]$. In our colony the attention deficit was also confirmed by PPI test as the main behav- 
Table 1

Matrix of the correlation among the AcH3K9 immunohistochemically stained brain areas.

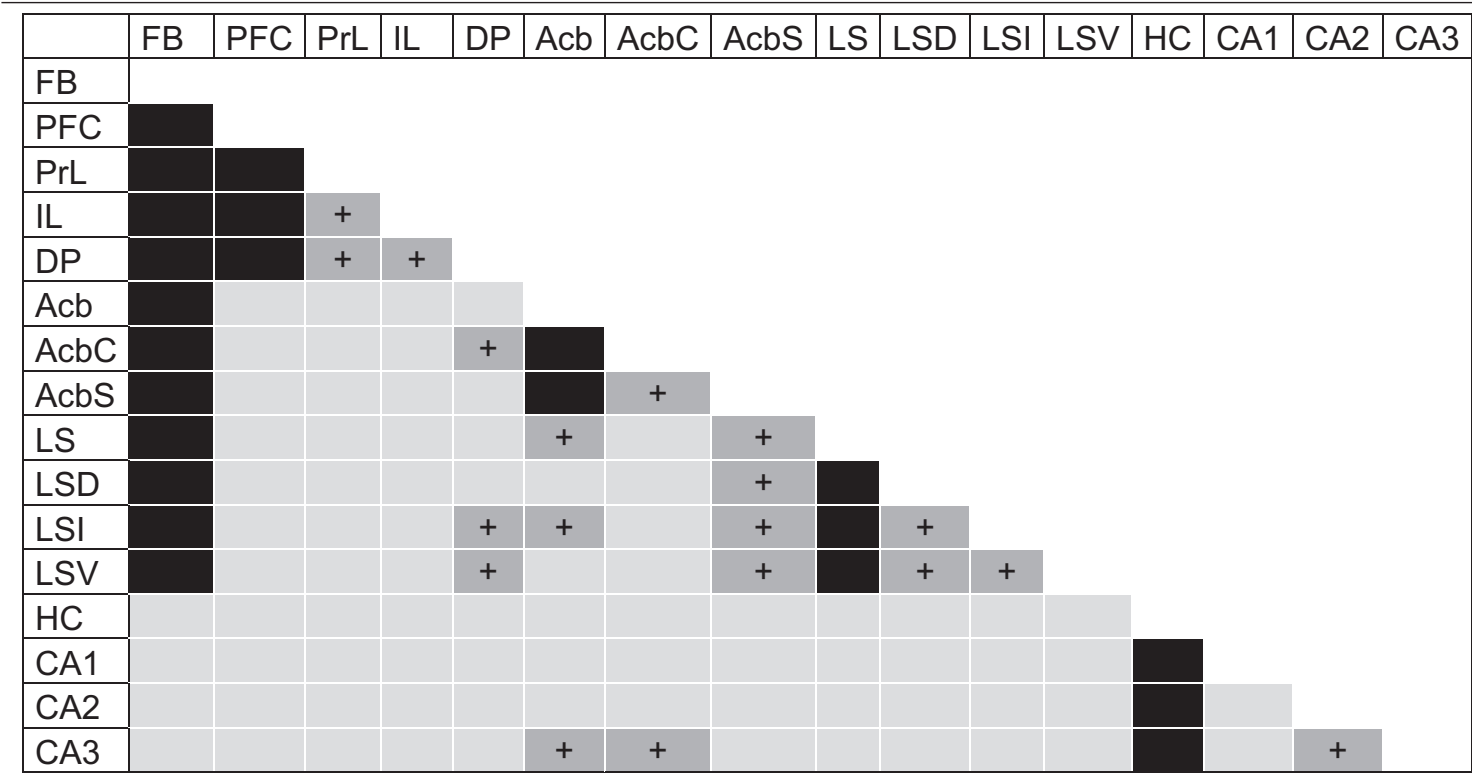

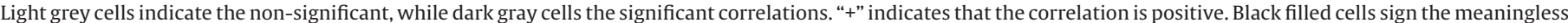

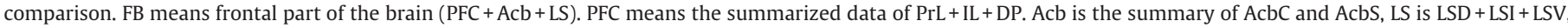
while $\mathrm{HC}$ is the summary of CA1 + CA2 + CA3.

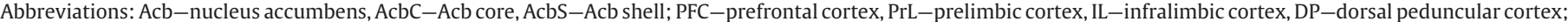
LS-lateral septum, LSD-LS dorsal part, LSI-LS intermediate part, LSV-LS ventral part; HC-hippocampus, CA1-3-cornu ammonis of hippocampus.

ioral model of SCZ used not only in preclinical, but also in clinical research $[67,68]$.

The negative correlation between PPI and PFC AcH3K9 immunoreactivity in our colony was in good agreement with the role of epigenome, especially histone acetylation, in cognitive processes $[69,70]$. Although in humans the methylation "maintaining" enzyme, DNMT1 [14,71], as well as the de novo methyltransferase DNMT3 [72] were increased in the PFC of SCZ patients, in Brattleboro rats an opposite change, namely a decrease was detectable in DNMT1 of the frontal region. Therefore we were focusing on acetylation, while methylation processes seemed to have subtle contribution to the development of SCZ-like symptoms in Brattleboro rats. Moreover, based upon our Western blot analysis, H3 rather than $\mathrm{H} 4$ acetylation seemed to be important. An elevated HDAC1 level in the PFC, observed in postmortem brain samples of SCZ patient [73], might contribute to reduced $\mathrm{H} 3$ acetylation in the FB of di/di animals, however, it was not examined in our study.We have chosen to study the acetylation of a single lysine residue (AcH3K9), because Aoyoma et al. [19] using a pharmacological model of SCZ (piperidine hydrochloride (PCP) in mouse) found decreased level of AcH3K9 in the PFC. Moreover, previous observation found a decrease of AcH3K9 in human SCZ patients [74]. Our results in di/di rats were in good agreement both with the pharmacological model and human data.

However, despite the GABAergic origin hypothesis [75] we were unable to find alteration in the GABA synthetizing enzyme, GAD1 mRNA level. Although deficit in GABAergic system is one of the most commonly described abnormality in SCZ patients [76], and GAD1 thought to be down regulated because of the increased level of DNMT1 [71], but in Brattleboro rats an enhanced rather than reduced GABA level was reported [77] in good agreement with the found lower DNMT1 levels. Therefore we might assume that the detected lower acetylation in the FB could decrease other gene expression leading to reduced adaptive capacity to the suddenly changing environment. As summarized in [14] alteration of DNA methylation may be involved in epigenetic alterations of the glutamate and serotonin neurotransmitter system as well. We have investigated the mRNA level of key component of these systems the VGLUT1 and 5HT2A receptor, respectively, but no significant changes were observed. Furthermore, we examined mRNA level of BDNF gene that known to play an important role in cognition. Previous studies showed the hypermethylation of its genes in the etiology and pathogenesis of SCZ [9], but we did not find significant alteration in di/di animals, either.

Both in human patients and animal models of SCZ dysfunction of the dopaminergic system was observed [78] and the currently used antipsychotics antagonize dopamine receptors [79]. In the PCP model of SCZ the low AcH3K9 caused dysfunction of the dopaminergic systems and the atypical antipsychotic clozapine ameliorated the AcH3K9 level mainly on D1 receptor positive cells in the PFC [19]. It is also known, that D1 signaling regulates histone modification [80] and we also have found significant positive correlation (see Table 1) in the number of AcH3K9 positive cells between elements of the dopaminergic system (DP, Acb, LS). Although we did not measured significant alteration in the mRNA level of dopamine degrading enzyme COMT neither in the FB nor in the $\mathrm{HC}$, we can hypothesize that in Brattleboro rats the lack of AVP induces epigenetic modification leading to disturbances of the dopaminergic system, which contributes to the SCZ-like behavioral alterations. Indeed, higher dopamine content $[81,82]$ and upregulated dopamine receptors [45] were reported in di/di animals.

In the following we have examined in details those brain areas, which are thought to be involved in the development of SCZ. We have found significant decrease in the number of AcH3K9 positive cells in the DP of di/di rats. The role of the DP is less known and investigated than the neighboring IL and PrL despite their structural similarities [83]. Ventral part of the PFC specifically responsible for a flexible shifting to new strategies related to spatial cues, furthermore-on the basis of its connections with autonomic centers-for the integration of internal physiological states with salient environmental cues for the guidance of behavior [84]. DP shares projections relevant to reward circuitry such as glutamatergic afferents to the ventral tegmental area [85]. Furthermore, the IL and DP both project heavily to the AcbS [86]. 
There is lots of evidence that the Acb (because its dopamine content) is involved in the pathology of SCZ $[87,88]$. Although alteration of dopamine receptors in the Acb was found in di/di rats [45], but we did not find significant genotype difference in the number of AcH3K9 labeled cells. It seems that in Brattleboro rat, AcH3K9 alteration is not involved in the development of symptoms, but changes at other lysine residues might have some importance.

LSV plays an important role in various behavioral processes [89], integrates sensory stimuli conveying this information to responsible brain areas to direct motivating behaviors. LSV, showing significantly lower AcH3K9 reactivity in di/di than control rats, was activated (measured by c-Fos immunochemistry) during PPI [90]. Medial PFC sends glutamatergic projections to LS [89], thus, the lower cell activity of DP induced by decreased acetylation might lead to reduced acetylation/activation of LSV neurons. LS is strongly interconnected with the HC predominantly by inhibitory GABAergic neurons [91], which connection has an established role in learning and memory [92]. Moreover, the septo-hippocampal (CA1) GABAergic neurons were activated during locomotion and salient sensory event in behaving mice [93].

Thus, it is not surprising, that reduced inhibitory GABAergic tone in the HC lead to enhanced pan-AcH3 and especially AcH3K9 level in the CA1 of di/di rats compared to control animals. According to the literature during $\mathrm{HC}$ dependent memory formation (e.g., contextual fear conditioning or NOR) AcH3 level increased in the CA1, while AcH4 was unaltered [69]. This suggests that $\mathrm{H} 3$ acetylation occurs during chronic events [9], like the chronic stress of diabetes insipidus in di/di rats. These data, along with postmortem analyses [55,73], suggested that histone modifications in the HC might also contribute to the behavioral alteration in SCZ through aberrant regulation of one or more genes. Indeed, epigenetic mechanisms were initially described for their ability to promote differentiation including neurogenesis and $\mathrm{HC}$ is one of the two regions in which generation of new functional neurons from neural stem cells occurs throughout the adult life. Adult hippocampal neurogenesis contributes to learning and memory, core features of SCZ [94,95].

Positive symptoms such as auditory hallucinations have been correlated with abnormal activation patterns in PFC [96], furthermore delusional states and negative symptoms (e.g., avolition and apathy) also appear to be involved in prefrontal dysfunction [97]. The volume of the gray matter [98] and the cerebral blood flow [99] is reduced in the PFC of SCZ patients, known as hypofrontality. Our SCZ model, the di/di Brattleboro rat has also smaller brain volume, compared to $+/+$ animals [100]. Although hyperlocomotion is thought to reflect positive symptom, but, despite some previous observations (in adults [101] and in pups $[102,103])$, we were unable to detect changes in locomotion not only in different test situations [104,105], but also during a longterm observation by biotelemetry for $24 \mathrm{~h}$. Nevertheless, when we used a hyperlocomotion-inducing NMDA antagonist (ketamine ip $10 \mathrm{mg} / \mathrm{kg} / 2 \mathrm{ml}$ saline right before the $15 \mathrm{~min}$ openfield test; a model of positive symptoms [106]) the di/di rats did not show an enhancement of locomotion (number of line crossing in control: $530.7 \pm 74.6$; in di/di: $335.7 \pm 63.2$ ), which can be supposed in an already SCZ-like subject [61].

\section{Conclusion}

We can propose that the AVP deficient Brattleboro rat strain is a valuable model (i) to study the development of SCZ-like behavior, to establish new test battery for SCZ, (ii) follow the changes in epigenetic state of affected genes, and (iii) test newly discovered antipsychotics. This is hotspot as influencing HDACs may provide therapeutic alternatives for treating many of the symptoms associated with SCZ, particularly cognitive deficits [107]. Our studies confirmed that no single gene, more probably fine changes in an array of molecules are responsible for the majority of SCZ cases.

\section{Acknowledgements}

This study was supported by Hungarian Research Found OTKA NN71629 to DZ; K109622 to KJK; 109744 to SzF and by Bolyai grant to DZ and VSz.

\section{References}

[1] D. Bhugra, Severe mental illness across cultures, Acta Psychiatr. Scand. Suppl. 429 (2006) 17-23

[2] T. Nagai, D. Ibi, K. Yamada, Animal model for schizophrenia that reflects gene-environment interactions, Biol. Pharm. Bull. 34 (2011) 1364-1368.

[3] American, Psychiatric, Association, Diagnostic and Statistical Manual of Mental Disorders (DSM- $\left.5^{\circledR}\right)(2013)$.

[4] A. Carlsson, M. Lindqvist, Effect of chlorpromazine or haloperidol on formation of 3 methoxytyramine and normetanephrine in mouse brain, Acta Pharmacol. Toxicol. 20 (1963) 140-144.

[5] J.M. van Rossum, The significance of dopamine-receptor blockade for the mechanism of action of neuroleptic drugs, Arch. Int. Pharmacodyn. Ther 160 (1966) 492-494

[6] Schizophrenia Working Group of the Psychiatric Genomics C, Biological insights from 108 schizophrenia-associated genetic loci, Nature 511 (2014) 421-427.

[7] D.M. Svrakic, C.F. Zorumski, N.M. Svrakic, I. Zwir, C.R. Cloninger, Risk architecture of schizophrenia: the role of epigenetics, Curr. Opin. Psychiatry 26 (2013) 188-195.

[8] D.P. Gavin, R.P. Sharma, Histone modifications, DNA methylation, and schizophrenia, Neurosci. Biobehav. Rev. 34 (2010) 882-888.

[9] N. Tsankova, W. Renthal, A. Kumar, E.J. Nestler, Epigenetic regulation in psychiatric disorders, Nat. Rev. Neurosci. 8 (2007) 355-367.

[10] A. Petronis, A.D. Paterson, J.L. Kennedy, Schizophrenia: an epigenetic puzzle? Schizophr. Bull. 25 (1999) 639-655.

[11] I.I. Gottesman, J. Shields, D.R. Hanson, Schizophrenia: The Epigenetic Puzzle, Cambridge University Press, Cambridge, England, 1982.

[12] C.L. Smith, A. Bolton, G. Nguyen, Genomic and epigenomic instability, fragile sites, schizophrenia and autism, Curr. Genom. 11 (2010) 447-469.

[13] G.L. Engel, The biopsychosocial model and the education of health professionals, Ann. N. Y. Acad. Sci. 310 (1978) 169-187.

[14] D. Zelena, Co-regulation and epigenetic dysregulation in schizophrenia and bipolar disorder, in: J. Minarovits, H.H. Niller (Eds.), Patho-Epigenetics of Disease, Springer Science+Business Media, 2012, pp. 281-347.

[15] S. Akbarian, Epigenetics of schizophrenia, Curr. Top. Behav. Neurosci. 4 (2010) 611-628.

[16] A. Must, Z. Janka, S. Horvath, Schizophrenia, environment and epigenetics, Neuropsychopharmacol. Hung. 13 (2011) 211-217.

[17] E. Li, Chromatin modification and epigenetic reprogramming in mammalian development, Nat. Rev. Genet. 3 (2002) 662-673.

[18] G.G. Brune, H.E. Himwich, Effects of methionine loading on the behavior of schizophrenic patients, J. Nerv. Ment. Dis. 134 (1962) 447-450.

[19] Y. Aoyama, A. Mouri, K. Toriumi, T. Koseki, S. Narusawa, N. Ikawa, et al., Clozapine ameliorates epigenetic and behavioral abnormalities induced by phencyclidine through activation of dopamine D1 receptor, Int. J. Neuropsychopharmacol. 17 (2014) 723-737.

[20] M.G. Melka, C.A. Castellani, B.I. Laufer, R.N. Rajakumar, R. O’Reilly, S.M. Singh, Olanzapine induced DNA methylation changes support the dopamine hypothesis of psychosis, J. Mol. Psychiatry 1 (2013) 19.

[21] E. Dong, D.R. Grayson, A. Guidotti, E. Costa, Antipsychotic subtypes can be characterized by differences in their ability to modify GABAergic promoter methylation, Epigenomics 1 (2009) 201-211.

[22] S.O. Frederiksen, R. Ekman, C.G. Gottfries, E. Widerlov, S. Jonsson, Reduced concentrations of galanin, arginine vasopressin, neuropeptide $Y$ and peptide YY in the temporal cortex but not in the hypothalamus of brains from schizophrenics, Acta Psychiatr. Scand. 83 (1991) 273-277.

[23] A. Jobst, S. Dehning, S. Ruf, T. Notz, A. Buchheim, K. Henning-Fast, et al., Oxytocin and vasopressin levels are decreased in the plasma of male schizophrenia patients, Acta Neuropsychiatr. 6 (2014) 347-355.

[24] J.K. Mai, K. Berger, M.V. Sofroniew, Morphometric evaluation of neurophysin-immunoreactivity in the human brain: pronounced inter-individual variability and evidence for altered staining patterns in schizophrenia, J. fur Hirnforschung 34 (1993) 133-154.

[25] I. Elman, S. Lukas, S.E. Shoaf, D. Rott, C. Adler, A. Breier, Effects of acute metabolic stress on the peripheral vasopressinergic system in schizophrenia, J. Psychopharmacol. 17 (2003) 317-323.

[26] L.H. Rubin, C.S. Carter, J.R. Bishop, H. Pournajafi-Nazarloo, L.L. Drogos, S.K. Hill, et al., Reduced levels of vasopressin and reduced behavioral modulation of oxytocin in psychotic disorders, Schizophr. Bull. 40 (2014) 1374-1384.

[27] O. Teltsh, K. Kanyas-Sarner, A. Rigbi, L. Greenbaum, B. Lerer, Y. Kohn, Oxytocin and vasopressin genes are significantly associated with 
schizophrenia in a large Arab-Israeli pedigree, Int. J.

Neuropsychopharmacol. 15 (2012) 309-319.

[28] R. Levin, U. Heresco-Levy, R. Bachner-Melman, S. Israel, I. Shalev, R.P. Ebstein, Association between arginine vasopressin 1a receptor (AVPR1a) promoter region polymorphisms and prepulse inhibition, Psychoneuroendocrinology 34 (2009) 901-908.

[29] V. Golimbet, M. Alfimova, L. Abramova, V. Kaleda, I. Gritsenko, Arginine vasopressin 1a receptor RS3 promoter microsatellites in schizophrenia: a study of the effect of the risk allele on clinical symptoms and facial affect recognition, Psychiatry Res. 225 (2015) 739-740.

[30] L. Forizs, Treatment of mental patients with antidiuretic hormone of the posterior pituitary, Dis. Nerv. Syst. 13 (1952) 44-47.

[31] F. Brambilla, G.P. Bondiolotti, M. Maggioni, A. Sciascia, W. Grillo, F. Sanna, et al., Vasopressin (DDAVP) therapy in chronic schizophrenia: effects on negative symptoms and memory, Neuropsychobiology 20 (1989) 113-119.

[32] F. Brambilla, E. Aguglia, R. Massironi, M. Maggioni, W. Grillo, R. Castiglioni, et al., Neuropeptide therapies in chronic schizophrenia: TRH and vasopressin administration, Neuropsychobiology 15 (1986) 114-121.

[33] S. Korsgaard, D.E. Casey, N.E. Damgaard Pedersen, A. Jorgensen, J. Gerlach, Vasopressin in anergic schizophrenia. A cross-over study with lysine-8-vasopressin and placebo, Psychopharmacology 74 (1981) 379-382.

[34] V.D. Bakharev, S.M. Tikhomirov, O.S. Papsuevich, G.I. Chipens, Use of vasopressin the treatment of the paranoid form of schizophrenia, Zhurnal Nevropatologii i Psikhiatrii Imeni SS Korsakova 84 (1984) 88-92.

[35] A.C. Iager, D.G. Kirch, L.B. Bigelow, C.N. Karson, Treatment of schizophrenia with a vasopressin analogue, Am. J. Psychiatry 143 (1986) 375-377.

[36] P. Linkowski, V. Geenen, M. Kerkhofs, J. Mendlewicz, J.J. Legros, Cerebrospinal fluid neurophysins in affective illness and in schizophrenia, Eur. Arch. Psychiatry Neurol. Sci. 234 (1984) 162-165.

[37] M.B. Goldman, G.L. Robertson, D.J. Luchins, D. Hedeker, G.N. Pandey, Psychotic exacerbations and enhanced vasopressin secretion in schizophrenic patients with hyponatremia and polydipsia, Arch. Gen. Psychiatry 54 (1997) 443-449.

[38] D. Ganten, D. Pfaff, Behavioral Aspects of Neuroendocrinology, Springer-Verlag, Berlin, Heidelberg, 1990.

[39] D. Feifel, K. Priebe, The effects of cross-fostering on inherent sensorimotor gating deficits exhibited by Brattleboro rats, J. Gen. Psychol. 134 (2007) $173-182$.

[40] D. Feifel, G. Melendez, P.D. Shilling, Reversal of sensorimotor gating deficits in Brattleboro rats by acute administration of clozapine and a neurotensin agonist, but not haloperidol: a potential predictive model for novel antipsychotic effects, Neuropsychopharmacology 29 (2004) 731-738.

[41] D. Feifel, K. Priebe, Vasopressin-deficient rats exhibit sensorimotor gating deficits that are reversed by subchronic haloperidol, Biol. Psychiatry 50 (2001) 425-433

[42] D. Feifel, S. Mexal, G. Melendez, P.Y. Liu, J.R. Goldenberg, P.D. Shilling, The brattleboro rat displays a natural deficit in social discrimination that is restored by clozapine and a neurotensin analog, Neuropsychopharmacology 34 (2009) 2011-2018.

[43] D. Feifel, G. Melendez, K. Priebe, P.D. Shilling, The effects of chronic administration of established and putative antipsychotics on natural prepulse inhibition deficits in Brattleboro rats, Behav. Brain Res. 181 (2007) $278-286$.

[44] M.D. Berquist Ii, S.M. Mooney-Leber, D. Feifel, A.J. Prus, Assessment of attention in male and female Brattleboro rats using a self-paced five-choice serial reaction time task, Brain Res. 1537 (2013) 174-179.

[45] P.D. Shilling, B. Kinkead, T. Murray, G. Melendez, C.B. Nemeroff, D. Feifel, Upregulation of striatal dopamine-2 receptors in Brattleboro rats with prepulse inhibition deficits, Biol. Psychiatry 60 (2006) $1278-1281$

[46] J. Cilia, J.E. Gartlon, C. Shilliam, L.A. Dawson, S.H. Moore, D.N. Jones, Further neurochemical and behavioural investigation of Brattleboro rats as a putative model of schizophrenia, J. Psychopharmacol. 24 (2010) 407-419.

[47] L.D. Selemon, N. Zecevic, Schizophrenia: a tale of two critical periods for prefrontal cortical development, Transl. Psychiatry 5 (2015) e623.

[48] H. Morishita, M. Kundakovic, L. Bicks, A. Mitchell, S. Akbarian, Interneuron epigenomes during the critical period of cortical plasticity: implications for schizophrenia, Neurobiol. Learn. Mem. 124 (2015) 104-110.

[49] A.C. Mitchell, Y. Jiang, C. Peter, S. Akbarian, Transcriptional regulation of GAD1 GABA synthesis gene in the prefrontal cortex of subjects with schizophrenia, Schizophr. Res. 167 (1-3) (2014) 28-34.

[50] N.V. Kraguljac, A. Srivastava, A.C. Lahti, Memory deficits in schizophrenia: a selective review of functional magnetic resonance imaging (FMRI) studies, Behav. Sci. 3 (2013) 330-347.

[51] E. Jodo, The role of the hippocampo-prefrontal cortex system in phencyclidine-induced psychosis: a model for schizophrenia, J. Physiol. Paris 107 (2013) 434-440.

[52] S.Y. Shu, Y.M. Wu, X.M. Bao, B. Leonard, Interactions among memory-related centers in the brain, J. Neurosci. Res. 71 (2003) 609-616.

[53] E. Costa, J.M. Davis, E. Dong, D.R. Grayson, A. Guidotti, L. Tremolizzo, et al., A GABAergic cortical deficit dominates schizophrenia pathophysiology, Crit. Rev. Neurobiol. 16 (2004) 1-23.

[54] S. Kimoto, H.H. Bazmi, D.A. Lewis, Lower expression of glutamic acid decarboxylase 67 in the prefrontal cortex in schizophrenia: contribution of altered regulation by Zif268, Am. J. Psychiatry 171 (2014) 969-978.
[55] F.M. Benes, B. Lim, D. Matzilevich, J.P. Walsh, S. Subburaju, M. Minns, Regulation of the GABA cell phenotype in hippocampus of schizophrenics and bipolars, Proc. Natl. Acad. Sci. U. S. A. 104 (2007) 10164-10169.

[56] D. Zelena, A. Domokos, S.K. Jain, R. Jankord, L. Filaretova, The stimuli-specific role of vasopressin in the hypothalamus-pituitary-adrenal axis response to stress, J. Endocrinol. 202 (2009) 263-278.

[57] E. Mikics, J. Baranyi, J. Haller, Rats exposed to traumatic stress bury unfamiliar objects-a novel measure of hyper-vigilance in PTSD models? Physiol. Behav. 94 (2008) 341-348.

[58] J. Varga, B. Klausz, A. Domokos, S. Kalman, M. Pakaski, S. Szucs, et al., Increase in Alzheimer's related markers preceeds memory disturbances: studies in vasopressin-deficient Brattleboro rat, Brain Res. Bull. 100 (2014) 6-13.

[59] M. Engelmann, C.T. Wotjak, R. Landgraf, Social discrimination procedure: an alternative method to investigate juvenile recognition abilities in rats, Physiol. Behav. 58 (1995) 315-321.

[60] A. Fodor, B. Klausz, O. Pinter, N. Daviu, C. Rabasa, D. Rotllant, et al., Maternal neglect with reduced depressive-like behavior and blunted c-fos activation in Brattleboro mothers, the role of central vasopressin, Horm. Behav. 62 (2012) 539-551.

[61] C.M. Powell, T. Miyakawa, Schizophrenia-relevant behavioral testing in rodent models: a uniquely human disorder? Biol. Psychiatry 59 (2006) 1198-1207.

[62] G.N. Brito, G.J. Thomas, S.I. Gingold, D.M. Gash, Behavioral characteristics of vasopressin-deficient rats (Brattleboro strain), Brain Res. Bull. 6 (1981) $71-75$.

[63] T.B. van Wimersma Greidanus, J. Jolles, D. De Wied, Hypothalamic neuropeptides and memory, Acta Neurochir. 75 (1985) 99-105.

[64] G. Colombo, C. Hansen, P.L. Hoffman, K.A. Grant, Decreased performance in a delayed alternation task by rats genetically deficient in vasopressin, Physiol. Behav. 52 (1992) 827-830.

[65] M. Engelmann, R. Landgraf, Microdialysis administration of vasopressin into the septum improves social recognition in Brattleboro rats, Physiol. Behav. 55 (1994) 145-149.

[66] A. Fodor, B. Barsvari, M. Aliczki, Z. Balogh, D. Zelena, S.R. Goldberg, et al., The effects of vasopressin deficiency on aggression and impulsiveness in male and female rats, Psychoneuroendocrinology 47 (2014) 141-150.

[67] R.D. Porsolt, P.C. Moser, V. Castagne, Behavioral indices in antipsychotic drug discovery, J. Pharmacol. Exp. Ther. 333 (2010) 632-638.

[68] M. Koch, Clinical relevance of animal models of schizophrenia, Suppl. Clin. Neurophysiol. 62 (2013) 113-120.

[69] J.M. Levenson, K.J. O’Riordan, K.D. Brown, M.A. Trinh, D.L. Molfese, J.D. Sweatt, Regulation of histone acetylation during memory formation in the hippocampus, J. Biol. Chem. 279 (2004) 40545-40559.

[70] J.M. Levenson, J.D. Sweatt, Epigenetic mechanisms in memory formation, Nat. Rev. Neurosci. 6 (2005) 108-118.

[71] M. Veldic, A. Guidotti, E. Maloku, J.M. Davis, E. Costa, In psychosis, cortical interneurons overexpress DNA-methyltransferase 1, Proc. Natl. Acad. Sci. U. S. A. 102 (2005) 2152-2157

[72] A. Zhubi, M. Veldic, N.V. Puri, B. Kadriu, H. Caruncho, I. Loza, et al., An upregulation of DNA-methyltransferase 1 and 3a expressed in telencephalic GABAergic neurons of schizophrenia patients is also detected in peripheral blood lymphocytes, Schizophr. Res. 111 (2009) 115-122.

[73] R.P. Sharma, D.R. Grayson, D.P. Gavin, Histone deactylase 1 expression is increased in the prefrontal cortex of schizophrenia subjects: analysis of the National Brain Databank microarray collection, Schizophr. Res. 98 (2008) $111-117$.

[74] D.P. Gavin, S. Kartan, K. Chase, D.R. Grayson, R.P. Sharma, Reduced baseline acetylated histone 3 levels, and a blunted response to HDAC inhibition in lymphocyte cultures from schizophrenia subjects, Schizophr. Res. 103 (2008) 330-332.

[75] K. Nakazawa, V. Zsiros, Z. Jiang, K. Nakao, S. Kolata, S. Zhang, et al. GABAergic interneuron origin of schizophrenia pathophysiology, Neuropharmacology 62 (2012) 1574-1583.

[76] S.F. Taylor, E. Demeter, K.L. Phan, I.F. Tso, R.C. Welsh, Abnormal GABAergic function and negative affect in schizophrenia, Neuropsychopharmacology 39 (2014) 1000-1008.

[77] B.E. Leonard, F. Ramaekers, H. Rigter, Monamines in brain and urine of rats with hereditary hypothalamic diabetes insipidus, Experientia 32 (1976) 901-902.

[78] A.Y. Deutch, The regulation of subcortical dopamine systems by the prefrontal cortex: interactions of central dopamine systems and the pathogenesis of schizophrenia, J. Neural Transm. Suppl. 36 (1992) 61-89.

[79] P.J. Harrison, The neuropathology of schizophrenia. A critical review of the data and their interpretation, Brain 122 (Pt 4) (1999) 593-624.

[80] F.A. Schroeder, K.L. Penta, A. Matevossian, S.R. Jones, C. Konradi, A.R. Tapper, et al., Drug-induced activation of dopamine $\mathrm{D}(1)$ receptor signaling and inhibition of class I/II histone deacetylase induce chromatin remodeling in reward circuitry and modulate cocaine-related behaviors, Neuropsychopharmacology 33 (2008) 2981-2992.

[81] A.R. Williams, R.J. Carey, M. Miller, Altered emotionality of the vasopressin-deficient Brattleboro rat, Peptides 6 (Suppl. 1) (1985) 69-76.

[82] M.G. Feenstra, F.G. Snijdewint, H. Van Galen, G.J. Boer, Widespread alterations in central noradrenaline, dopamine, and serotonin systems in 
the Brattleboro rat not related to the local absence of vasopressin, Neurochem. Res. 15 (1990) 283-288.

[83] K. Brodmann, L.J. Garey, Brodmann's: Localisation in the Cerebral Cortex, Springer, 2006.

[84] C.A. Heidbreder, H.J. Groenewegen, The medial prefrontal cortex in the rat: evidence for a dorso-ventral distinction based upon functional and anatomical characteristics, Neurosci. Biobehav. Rev. 27 (2003) 555-579.

[85] S. Geisler, C. Derst, R.W. Veh, D.S. Zahm, Glutamatergic afferents of the ventral tegmental area in the rat, J. Neurosci. 27 (2007) 5730-5743.

[86] J.S. Brog, A. Salyapongse, A.Y. Deutch, D.S. Zahm, The patterns of afferent innervation of the core and shell in the accumbens part of the rat ventral striatum: immunohistochemical detection of retrogradely transported fluoro-gold, J. Comp. Neurol. 338 (1993) 255-278.

[87] J.G. Csernansky, M.E. Bardgett, Limbic-cortical neuronal damage and the pathophysiology of schizophrenia, Schizophr. Bull. 24 (1998) 231-248.

[88] H. Moore, A.R. West, A.A. Grace, The regulation of forebrain dopamine transmission: relevance to the pathophysiology and psychopathology of schizophrenia, Biol. Psychiatry 46 (1999) 40-55.

[89] T.P. Sheehan, R.A. Chambers, D.S. Russell, Regulation of affect by the lateral septum: implications for neuropsychiatry, Brain Res. Brain Res. Rev. 46 (2004) 71-117.

[90] G. van Luijtelaar, P.F. Fabene, N. de Bruin, C. Jongema, B.A. Ellenbroek, J.G. Veening, Neural correlates of sensory gating in the rat: decreased Fos induction in the lateral septum, Brain Res. Bull. 54 (2001) 145-151.

[91] M. Burjanadze, S. Mataradze, K. Rusadze, N. Chkhikvishvili, M. Dashniani, Selective lesion of GABA-ergic neurons in the medial septum by GAT1-saporin impairs spatial learning in a water-maze, Georgian Med. News 5 (2015) 9-64.

[92] J.J. Roland, A.L. Stewart, K.L. Janke, M.R. Gielow, J.A. Kostek, L.M. Savage, et al., Medial septum-diagonal band of Broca (MSDB) GABAergic regulation of hippocampal acetylcholine efflux is dependent on cognitive demands, J. Neurosci. 34 (2014) 506-514.

[93] P. Kaifosh, M. Lovett-Barron, G.F. Turi, T.R. Reardon, A. Losonczy, Septo-hippocampal GABAergic signaling across multiple modalities in awake mice, Nat. Neurosci. 16 (2013) 1182-1184.

[94] H. van Praag, A.F. Schinder, B.R. Christie, N. Toni, T.D. Palmer, F.H. Gage, Functional neurogenesis in the adult hippocampus, Nature 415 (2002) 1030-1034.

[95] W. Deng, J.B. Aimone, F.H. Gage, New neurons and new memories: how does adult hippocampal neurogenesis affect learning and memory? Nat. Rev. Neurosci. 11 (2010) 339-350.
[96] S.S. Shergill, M.J. Brammer, S.C. Williams, R.M. Murray, P.K. McGuire, Mapping auditory hallucinations in schizophrenia using functional magnetic resonance imaging, Arch. Gen. Psychiatry 57 (2000) 1033-1038.

[97] S. Heckers, D. Goff, D.L. Schacter, C.R. Savage, A.J. Fischman, N.M. Alpert, et al., Functional imaging of memory retrieval in deficit vs nondeficit schizophrenia, Arch. Gen. Psychiatry 56 (1999) 1117-1123.

[98] D.R. Weinberger, M.F. Egan, A. Bertolino, J.H. Callicott, V.S. Mattay, B.K. Lipska, et al., Prefrontal neurons and the genetics of schizophrenia, Biol. Psychiatry 50 (2001) 825-844.

[99] D.H. Ingvar, G. Franzen, Distribution of cerebral activity in chronic schizophrenia, Lancet 2 (1974) 1484-1486.

[100] G.J. Boer, C.M. Van Reenen-Verberg, H.B. Uylings, Impaired brain development of the diabetes insipidus Brattleboro rat, Brain Res. 255 (1982) 557-575.

[101] A.R. Williams, R.J. Carey, M. Miller, Behavioral differences between vasopressin-deficient (Brattleboro) and normal Long-Evans rats, Peptides 4 (1983) 711-716

[102] D. Zelena, Z. Mergl, G.B. Makara, Postnatal development in vasopressin deficient Brattleboro rats with special attention to the hypothalamo-pituitary-adrenal axis function: the role of materna genotype, Int. J. Dev. Neurosci. 27 (2009) 175-183.

[103] J.C. Schank, Early locomotor and social effects in vasopressin deficient neonatal rats, Behav. Brain Res. 197 (2009) 166-177.

[104] M. Mlynarik, D. Zelena, G. Bagdy, G.B. Makara, D. Jezova, Signs of attenuated depression-like behavior in vasopressin deficient Brattleboro rats, Horm. Behav. 51 (2007) 395-405.

[105] D. Balazsfi, O. Pinter, B. Klausz, K.B. Kovacs, A. Fodor, B. Torok, et al., Restoration of peripheral V2 receptor vasopressin signaling fails to correct behavioral changes in Brattleboro rats, Psychoneuroendocrinology 51 (2015) 11-23.

[106] A. Adell, L. Jimenez-Sanchez, X. Lopez-Gil, T. Romon, Is the acute NMDA receptor hypofunction a valid model of schizophrenia? Schizophr. Bull. 38 (2012) 9-14

[107] M. Weiwer, M.C. Lewis, F.F. Wagner, E.B. Holson, Therapeutic potential of isoform selective HDAC inhibitors for the treatment of schizophrenia, Future Med. Chem. 5 (2013) 1491-1508. 